Version accepted for publication in Water and Environment Journal

\title{
Trends in the use of large wood in UK river restoration projects: insights from the National River Restoration Inventory
}

\author{
Cashman, M. ${ }^{1,2^{*}}$, Wharton, G. ${ }^{2}$, Harvey, G. L. ${ }^{2}$, Naura, M. ${ }^{3}$ and Bryden, A. ${ }^{3}$ \\ ${ }^{1}$ School of Geography, Queen Mary University of London \\ ${ }^{2}$ Current affiliation: United States Geological Survey, Maryland, Delaware and District of \\ Columbia Water Science Center \\ ${ }^{3}$ UK River Restoration Centre \\ *corresponding author (mcashman@usgs.gov)
}

\begin{abstract}
Large Wood (LW) is increasingly employed in river restoration to promote physical habitat heterogeneity and ecological diversity. To explore how LW has been used in restoration schemes across the UK in recent decades, we analysed data on $912 \mathrm{LW}$ projects archived in the UK's National River Restoration Inventory (NRRI). The number of LW schemes has continued to increase following the earliest records in the 1990s, largely tracking overall trends in river restorations. LW projects have been predominantly located in lowland, rural streams, although there has been a notable cluster in and around London. LW projects have mainly revolved around the desire to deliver hydromorphological improvements and specifically the creation of fish habitat. Most schemes used LW in simple deflector forms despite the growing scientific evidence of the benefits of using structurally complex LW. Post project monitoring has been limited and mostly restricted to photographic records.
\end{abstract}

Key Words: fish habitat, Large Wood, National River Restoration Inventory, river restoration, River Restoration Centre 


\section{Introduction and Background}

Wood, both living and dead, is a naturally occurring feature of rivers where it acts as an ecosystem engineer, creating and sustaining habitats that are physically and ecologically diverse (Gurnell et al., 1995; 2002; this volume; Pilotto et al., 2014) and increasing the availability and diversity of food resources for stream consumers (Cashman et al., 2016). A growing body of scientific evidence on the multiple co-benefits of wood in rivers is gradually changing the negative perception that rivers with wood are less attractive (untidy) and more hazardous (Piégay et al., 2005; Chin et al., 2014; Wohl, 2017). As a result, the long-held practice of removing wood from rivers (Wohl, 2014), such as to facilitate navigation and increase conveyance of flows and sediments, is now being challenged and there is increasing emphasis on promoting the (re)introduction of instream wood features as part of restoration schemes to assist habitat recovery. Large wood reintroduction or 'rewilding' projects have been shown to deliver rapid improvements to biodiversity across food webs (Thompson et al., 2017) and may, therefore, play an important role in meeting legislative requirements such as the Water Framework Directive goals of Good Ecological Status (GES) or Good Ecological Potential (GEP) by 2027 (EC 2000; 2014; RRC 2018). In England, DEFRA's $£ 92$ million funding initiative to improve the physical and ecological status of rivers and wetlands (DEFRA, 2011) added further impetus to the growing number of restoration projects, including those using relatively low-cost instream measures such as wood to deliver habitat improvements (Smith et al., 2014a; Grabowski et al., this volume).

In restoration schemes, most wood is (re)introduced as single pieces of Large Wood (LW), defined as wood larger than $10 \mathrm{~cm}$ in diameter and $1 \mathrm{~m}$ in length (Gurnell et al., 2002). Habitat benefits increase with the complexity of wood accumulations that resemble natural wood features (e.g. Harvey et al., 2018) but even simple LW structures can promote habitat heterogeneity and macroinvertebate diversity (Pilotto et al., 2016). The habitat benefits of LW can also extend from the micro-scale of a few centimetres, through mesohabitat and reach scale up to the landscape scale $\left(10-100+\mathrm{km}^{2}\right)($ Wohl, 2017).

Alongside habitat restoration measures, there has beena gradual emergence in recent years of more environmentally-sensitive catchment-based approaches to flood risk management (Addy et al., 2016). In the UK, these have been promoted by policies such as Making Space for Water (DEFRA, 2004) and the recent DEFRA and Environment Agency initiative Working with Natural Processes (WwNP) to deliver Natural Flood Management (NFM) (EA 2017). NFM approaches include projects identifying locations in river networks where LW (ranging from simple "leaky" barriers to more structurally complex natural LW jams) can be installed to "slow the flow" and help reconnect channels and their floodplains to provide more significant gains in flood storage and flow attenuation (Dadson et al., 2017). Evidence gathering is a key element of this on-going work (EA, 2017). 
Learning the lessons from past use of LW in river restoration projects is fundamental to developing clear guidance on how to design, implement, and manage future projects for the delivery of multiple co-benefits (see Grabowski et al., this issue). While continuing to clearly communicate the benefits of LW in restoration to combat negative perceptions and avoid conflict between stakeholder groups (Chin et al., 2014), guidance must be careful to show how risks, particularly concerns over LW mobility, can be mitigated. Such guidance might usefully follow, for example, the decision checklist approach for hazard evaluation suggested by Wohl et al. (2016).

A necessary first-step to learn from past projects is to better understand the range of restoration projects using LW that have already been implemented, especially the contextual information of motivating drivers, project designs, and monitoring approaches. In the UK, the River Restoration Centre (RRC) has managed the National River Restoration Inventory (NRRI) since 1998 as the national database for information on river restoration projects. Although submission is voluntary, the RRC takes an active role in seeking submissions and following-up on known recent restoration works, resulting in a current database of 4894 records submitted by groups such as the Environment Agency, Scottish Environmental Protection Agency, National Resources Wales, Northern Ireland Rivers Agency, River Trusts, National Trust, Natural England, and many other stakeholder groups in the restoration community. The database contains 145 information fields, but the key and most populated fields are: project summary information, including information on catchment characteristics; implementation techniques; themes, drivers and objectives; project partners; monitoring and evaluation methods; and costs.

This paper uses NRRI data to examine where and how LW has been used and monitored in river restoration projects throughout the UK, covering the full temporal span of project entries in the database. The insights gained from the analysis of this broad-scale database provide a timely contribution to emerging guidance on the use of LW in river management to ensure that optimum benefits are realised and risks reduced. This is especially important as we anticipate LW being employed in a greater number of projects, for both habitat restoration and natural flood management, and across a wider range of river types in the coming years.

\section{Methods}

The National River Restoration Inventory was accessed during March 2018 and searched to identify restoration projects using LW based on the inclusion of the terms "wood", "deflector" or "groyne" in the "Project Summary" field, as well as any entry citing Project Aim 1.12 "Current deflectors/concentrators to create habitat and flowdiversity." These projects were then subject to manual validation to ensure they include the use of instream wood features (e.g. removing projects such as those using wood fencing to exclude livestock). As not all wood projects contained entries for all information fields, sample sizes varied for the different analyses.

Fields of interest within the database contained different data types. Some fields had predefined responses (i.e. single or multiple selections) and were analysed according to the sum of responses for each individual selection. Entry fields with short custom-text, such as statements 
on "Project Partners", were examined and responses summed across common groups (e.g. statutory organizations, charities) prior to analysis.

The Project Summary field allowed for paragraphs of custom-text to be entered to capture the background conditions influencing the restoration project. This field was queried using ngram text mining analysis, with stop words removed, using the TidyText package (Silge and Robinson, 2016) in R (R Core Team, 2018). N-grams represent the number ( $n$ ) of words in keyword phrases, with unigrams, bigrams, and trigrams identifying single-word, double-word, and triple-word phrases, respectively. $\mathrm{N}$-grams are units of analysis commonly used in text-mining and language recognition studies (Cavnar and Trenkle, 1994; Pak and Paroubek, 2010) to identify not only commonly used words, but larger concepts, ideas, and sentiment across bodies of textual data. In this study, unigrams, bigrams, and trigrams were created from each restoration scheme's Project Summary entry, and the number of restoration schemes that contained at least one usage of each $n$-gram was then summed, to obtain frequency of n-gram usage, representing the most common themes influencing the restoration projects using large wood. In addition, a correlation matrix of unigrams referenced in at least 200 project schemes was created (i.e. the correlation that a unigram would co-occur within the Project Summary description of the same scheme). A correlation network plot for those words with correlations greater than 0.3 was then created to identify thematic clusters of restoration types based on words used in the Project Summary.

\section{Results}

After data cleaning, the final search for wood projects in the NRRI database yielded 912 individual wood restoration projects, from the current total archive of 4894 projects. Interestingly, the first entry in the database is from 1960 for a project on the River Clwyd, Wales, which used log and brush bundles as part of a scheme to deliver bank protection and shoal management. However, wood only starts to become a notable feature of restoration schemes from 1990 followed by a step change increase after 2008 (Figure 1). This observed increase in the number of restoration schemes using wood has tracked broader patterns in restoration implementation, maintaining around one fifth of all restoration schemes. The total number of wood projects archived in the NRRI continues to grow but, as there is typically a lag time in data entry of 2-3 years after the project start, we show the trend up to 2015.

The NRRI database also reveals some interesting patterns in the geographical location and catchment characteristics of restoration projects incorporating wood (Figures 2-5). A geographic comparison of woodprojects of the two decades following the conclusion of the EU LIFE River Restoration Demonstration Projects (1995-2005; 2006-2015) indicates that the large increases in projects from 2006-2015 were not evenly distributed across the UK (Figure 2 ). While there remains a continued focus on lowland sites in the south east of England, including sites in and around London and from the New Forest to Dorset, there was an expansion in the number of projects for rivers in the Midlands, the north of England, and Northern Ireland, and very little growth in Scotland. The lowland bias of restoration projects using wood is revealed by the strong positive skew in the elevation data (Figure 3). The vast 
majority of wood projects (79\%) have been undertaken in catchments with maximum elevations of less than $100 \mathrm{~m} \mathrm{ASL}$, with the peak number of schemes at elevations up to c. $50 \mathrm{~m}$ $A S L$, although in the areas of lowest elevation around sea level fewer than 50 schemes were recorded. Beyond these lowland catchments, there is a clear trend of fewer schemes with increasing elevations and only a very small percentage of projects $(7 \%)$ have been recorded at elevations above $200 \mathrm{~m}$ ASL. Restoration projects using wood have also been predominantly undertaken on sedimentary geology (63\% of all projects; Figure 4 ) with a third on chalk and only c. $2 \%$ on hard rocks, aligning with the geographical locations of projects (Figures 2 and 3 ). Although most restoration projects using wood have been undertaken in catchments with arable land use (grassland and crops), a significant number of projects ( $>100$ ) were also completed in suburban and urban areas, and many fewer projects $(<50)$ were undertaken within woodland areas (Figure 5).

Analysis of the main NRRI entry fields revealed patterns in why projects were undertaken, the restoration techniques, the stakeholders involved, and the monitoring approaches.

Interrogation of the Project driver/theme defined-selection input fields revealed a large range of motivations for restoration projects using wood, encompassing drivers to improve the physical, biological, chemical, social and economic aspects of rivers (Figure 6). However, Habitat and Biodiversity clearly emerged as the main driver, cited by over 700 studies. Fisheries, Hydromorphology, and Flood Risk Management together with Habitat and Biodiversity make up the top four drivers, cumulatively accounting for $75 \%$ of all listed drivers. Interestingly, Social benefits was the fifth most common driver of wood projects, resonating with the significant number of projects undertaken in urban and suburban areas, including the Greater London cluster (Figures 2 and 5).

Projects involving wood cite a total of 19 restoration techniques, in addition to "large wood" itself, indicating that wood is commonly used in combination with many additional restoration techniques (Figure 7). The most common techniques listed were the creation of backwaters, installation of flow deflectors and creation of two-stage channels. Importantly, use of structurally simple "flow deflectors" in projects was far more common (>200 citations) than the use of "large wood" (< 50 citations) which may include more structurally complex wood features.

The partnership approach, which is a key feature of UKriver restoration schemes, also characterizes the wood projects archived in the NRRI. A total of 338 partners across both public and private sectors were involved with government agencies, charitable trusts (in particular wildlife, river, and woodland trusts), and other NGOs representing the three most common groups (Figure 8). Government agencies were the most common partners, with $>150$ projects citing the Environment Agency or Natural England as a major partner. Other government agencies included Natural Resources Wales, the Scottish Environmental Protection Agency, the Northern Ireland Rivers Agency, and the Forestry Commission. Of the charitable trusts, the Wildlife Trusts were the most commonly involved, although River Trusts, Woodland Trusts, and other locational Trusts were also common partners. Other NGOs were a significant third category and primarily comprised of local partnerships and action groups (e.g. Chelmer and Blackwater Catchment Partnership, the Craven Conservation Group, Riverfly Partnership). 
However, it is important to note that this category contained over 106 individual partners, with no individual partner involved in more than 17 projects.

Details on monitoring approaches were entered as open text in the NRRI and only listed for 276 out of the 912 wood projects (Figure 9). Techniques were wide ranging covering physical and biological attributes but some key trends emerged. Photographic surveys were the most commonly used approach followed by fisheries surveys, and reconnaissance survey methods, with both River Habitat Survey and River Corridor Survey approaches cited.

The text-mining $\mathrm{n}$-gram analysis of the custom Project Summary field identified several key themes referenced across the 912 entries for the large wood restoration projects in the NRRI. The unigram (Figure 10a) identifies the most commonly used words in the project summaries and clearly shows habitat as the most referenced theme, with flow, fish and fisheries also within the top 12 responses. Figure 10a also highlights some key project drivers and themes, including flood, and restoration techniques such as use of gravel, wood(y), and deflectors, consistent with Figures 6 and 7, respectively. The bigram results (Figure 10b) identifying double word phrases provide additional contextual information. After woody debris, water quality was the second most commonly used bigram, and diffuse pollution also appears within the top 10. Fisheries habitat provides contextual information to the habitat unigram, indicating habitat restoration directed to fisheries. Similarly, brown trout, wild trout, spawning habitat, fish passage, and habitat fisheries all feature within this list, further revealing considerable emphasis on habitat creation or enhancement for fish (see also Figure 6). Bank erosion also appeared to be an important concern, being the fourth-most referenced bigram. Although lower on the list, flow deflectors and low flows provide additional insight, namely that the restorations using wood are related to enhancement of flow heterogeneity. Flood, previously referenced by the unigram analysis, is contextualized by both flood risk and flood defence. The Environment Agency is also a noticeable bigram, reflecting its major role as a project partner in wood projects (Figure 8).

Usage of full trigrams (three-word phrases) were relatively rare throughout the Project Summaries $(n<60)$, yet still provide further detailed contextual information (Figure 10c). Significantly, Water Framework Directive, a key driver for river restoration, was the most common referenced trigram. Trigrams associated with water quality (i.e. reduce diffuse pollution, poor water quality, habitats diffuse pollution), hydromorphology (i.e. barrier mitigation of morphology, low flow channel, habitat poor hydrology), sediment and erosion (i.e. bank erosion habitat, bank erosion fisheries), and flood management (i.e. flood defence habitat, flood risk management, and natural flood management) were all common.

The correlation network plot, which links common key words that co-occur within Project Summary descriptions, identified several key themes and types of restoration using LW (Figure 11). On the right-side of the network, a fisheries cluster was identified through main motivation linked to fisheries and nearby improve, trout, spawning, fish, and habitat. A cluster of hydromorphological descriptors in the top-left of the network included low, flow, channel, diversity, gravel, bed, create, marginal, vegetation, and bank erosion. Hydromorphological descriptors were not directly linked to fisheries but were indirectly linked through the co-usage 
of habitat by both groups. The bottom-left of the network identified two small side-clusters, one for natural flood management (restoration, natural, flood, floodplain, and woodland), and management of upland diffuse pollution (catchment, reduce, diffuse, pollution, riparian). Woody debris and tree plantings were commonly referenced but not explicitly linked to any individual thematic clusters.

\section{Discussion}

The RRC's National River Restoration Inventory is an invaluable repository and broad-scale database of river restoration schemes and provides a unique opportunity for assessing trends in the use of wood in river restoration. From a current total archive of 4894 schemes, our analysis revealed 912 individual river restoration projects citing the use of wood. The number of projects using wood has broadly tracked the overall increase in restoration projects since 1990 (reported by Smith et al., 2014a) with the number of wood projects as a proportion of all schemes remaining stable through time. The step change increase in all projects and those specifically using wood from 2008 is likely linked to a range of legislative and policy drivers, as summarised by Smith et al. (2014a). The Water Framework Directive (EC 2000) promoting habitat improvements and, more recently, the Floods Directive (EC 2007) and the Flood and Water Management Act (2010) giving an impetus to more sensitive flood risk management and NFM initiatives are particularly significant. The growing body of scientific literature on the benefits of LW in rivers over the past decade is also gradually changing the negative perceptions of wood in rivers (Wohl, 2017) as river scientists increasingly engage in restoration projects alongside a wide range of stakeholder groups including volunteers from local communities.

The observed geographical spread of wood projects in the UK, with the highest densities in the south and east of England including London, follows the broad patterns for river restoration projects as a whole, corresponding closely with those reported by Smith et al. (2014b) for NRRI data entries up to 2011. The lowland concentration of wood projects probably also reflects a growing confidence in using LW in lower energy streams, such as chalk streams (a river typology which accounts for a disproportionate one-third of the wood projects in our analysis) where the perceived risk of mobility and potential risk to infrastructure is lower compared to upland, higher energy rivers. Smith et al. (2014a) also found more instream measures (such as the use of LW) and fewer larger-scale morphological alterations in the restoration projects on Chalk rivers. As more lowland projects are undertaken and evidence of the benefits are communicated (e.g. Thompson et al., 2017; Harvey et al., 2018), this trend is likely to continue.

Although the majority of wood projects were implemented in rural land use settings (grassland and cropland), we identified more than 100 in suburban and urban areas and a dense cluster of projects in and aroundLondon (see also Smith et al., 2014b). These trends likely reflect the large number of impacted rivers which have employed instream measures including LW where space is limited for larger-scale morphological changes, such as re-meandering. The use of LW in urban river restoration schemes can help deliver habitat improvements and work towards meeting the WFD goals of GEP for Heavily Modified Water Bodies. The large number of projects 
in urban and suburban land uses, combined with the identification of social benefits as an important driver, is perhaps also indicative of a favourable shift in the public perceptions of wood in rivers (Piégay et al., 2005; Chin et al., 2014). Counterintuitively, woodland areas record much lower numbers of restoration projects using wood, but this needs to be placed in the context of the limited coverage of woodland in the UK, representing only 13\% (3.17 million hectares) of the total land area (www.forestry.gov.uk; statistics at $14^{\text {th }}$ June 2018). However, these sites offer opportunities for natural recruitment and replenishment of wood and the potential for the longer-term sustainability of instream wood structures (see Ruiz-Villanueva et al., 2016 for details on the wood cycle).

The identification of Habitat and Biodiversity as the key driver for wood projects, and the emerging importance of Hydromorphology, is likely reflecting the significant impact of the WFD requirement for Good Ecological Status or Good Ecological Potential in Heavily Modified Water Bodies. The NRRI analysis also appears to be capturing the increasing use of wood in river restoration projects for the delivery of Natural Flood Management. Text mining revealed additional context and deeper insights into the implementation of these wood projects, with the network plot indicating that projects, or at least their descriptions, clustered into several distinct themes. These key themes included restoration of fish habitat, hydromorphology, and flood management, corresponding with key drivers. Erosion, water quality and pollution issues also emerged as another smaller, yet notable, theme of projects using wood, reflecting increasing attempts to use river restoration to improve water and sediment quality in both rural and urban catchments (RRC, 2018). While projects may have indicated multiple Project drivers elsewhere in the NRRI, the network plot from Project Summary descriptions indicated projects were typically described by a single theme, with minimal overlap (at least in the co-occurrence of words) to other themes. This may indicate the singular background or focus of individual project managers in the description of their project, even if other co-benefits and themes were recognized on a defined list of drivers or themes to select elsewhere in the NRRI.

Wood has been used in many ways in the restoration of rivers in the UK, including incorporation into a wide range of additional restoration techniques (such as backwater creation and two stage flood channels) alongside those that directly introduce wood or woodrelated features (i.e. large wood and flow deflectors). This reflects the wide range of drivers for projects undertaken across the UK with differing catchment and river characteristics. Notably, projects appear to favour simpler flow deflectors over the use of (potentially) more structurally complex 'large wood' features. While simple flow structures can promote habitat improvements and increase biodiversity (Pilotto et al., 2016), more complex wood features that mimic natural wood may have the potential to deliver increased hydromorphological and ecological benefits (e.g. Cashman, 2014; Thompson et al., 2017; Harvey et al., 2018). Further research is required from a range of river types in different catchment settings to support the move away from simple wood structures (e.g. cleaned single logs fixed into position). This is particularly important in the context of the design and installation of "leaky barriers" as part of NFM programmes which also need to demonstrate other co-benefits besides flood mitigation.

River restoration in the UK, from its earliest beginnings as the River Restoration Project over 20 years ago, is characterized by the involvement of multiple partners. The Catchment Based 
Approach ( $\mathrm{CaBA}$ ) promoting catchment partnerships and the growth of river trusts strengthens this approach and ensures that restoration projects continue to go forward through multipartner schemes, involving much-needed local stakeholder engagement and buy-in. Reflecting these overall trends, more than 300 organizations have been involved in wood projects in the UK, most commonly government agencies, particularly the Environment Agency and Natural England, and charitable Trusts, but with a very important contribution from a diverse group of NGOs including local partnerships and action groups.

The importance of monitoring and appraisal in river restoration to ensure that lessons are learned from past schemes has been widely stated over many decades (e.g. Kondolf, 1998; Downs and Kondolf, 2002; Palmer et al., 2005). With the ever-increasing number of stakeholders and, in particular, the greater involvement of community-based groups and Citizen Science, it is even more imperative to learn from the evidence of past projects (Smith et al., 2014a). A range of monitoring techniques are reported in the NRRI but less than one third of all wood projects provided any information on monitoring and evaluation. The most common approaches were repeat photography, fisheries surveys, and reconnaissance field surveys for physical habitat, followed by a range of other biological surveys (plants, invertebrates and diatoms). While these methods offer important low-cost options for the post-project appraisal stage of projects when funds are notoriously low, the lack of more in-depth assessments of project outcomes poses problems for the development of best practice. For example, Morandi et al. (2014) identified that projects with poorer evaluation strategies tended to draw the most positive conclusions, while more ambitious monitoring programmes generated more ambiguous conclusions. This may suggest the potential for benefits to be overstated as a result of insufficient monitoring strategies.

Unfortunately, funding for monitoring and appraisal is unlikely to increase in the future and only a small number of restoration projects can be studied in detail. However, to widen the spatial and temporal dimensions of our knowledge base on the use of wood in river restoration we need to gather evidence from as large a range of completed projects as possible. As demonstrated in this study, the interrogation of broad-scale datasets like the NRRI by analysing frequently indicated responses and text mining can provide some valuable insights (see also Smith et al., 2014b). This approach can serve as a complement to metadata analyses of the literature, as suggested by Wohl (2017), to address important knowledge gaps in the use of wood in river restoration.

\section{Conclusions:}

1. UK river restoration projects using wood have shown a notable increase since 2008 and are predominantly found in lowland, rural catchments, with a disproportionate focuson chalk streams, and notable implementation in urban and suburban locations.

2. While government agencies, charitable trusts, and other NGOs were the three most common partner groups, the wide range of local NGOs shows the widespread use and success of local stakeholder engagement. 
3. Fish habitat, hydromorphological diversity, flood management, and water quality improvements emerged as distinct themes in the implementation and description of wood projects in the NRRI.

4. Despite habitat creation being a key driver, particularly for biodiversity and fisheries, the use of structurally-simple deflectors, rather than more structurally-complex large wood, dominates the NRRI entries on restoration techniques.

5. Restoration monitoring was limited and dominated by photographs, fisheries surveys, and visual habitat assessments.

6. Analysis of broad-scale databases, such as the NRRI, can provide valuable insights and help guide future restoration practice.

\section{Acknowledgements}

We are grateful to: the SMART Joint Doctoral Programme (Science for Management of Rivers and their Tidal systems), financed by the Erasmus Mundus Programme of the European Union, which funded Matthew Cashman's doctoral research which included the NRRI analysis; to the RRC for access to the NRRI and assistance with the analysis; and to Ed Oliver for help producing the Figures. The authors have no conflict of interests.

\section{References}

Addy, S., Cooksley, S., Dodd, N., Waylen, K., Stockan, J., Byg, A. and Holstead K. (2016) River restoration and biodiversity: Nature-based solutions for restoring rivers in the UK and Republic of Ireland. Aberdeen: CREW (Scotland's Centre of Expertise for Waters): CRW2014/10. Available at: http://www.crew.ac.uk/publication/river-restoration http://www.therrc.co.uk/manualriver-restoration-techniques [accessed 7 January 2018].

Cavnar, W.B. and Trenkle, J.M. (1994) N-gram-based text categorization. In: Proceedings of Third Annual Symposium on Document Analysis and Information Retrieval (SDAIR-94), Las Vegas, pp 161-175.

Cashman, M.J. (2014) The effect of large wood on river physical habitat and nutritional dynamics. Unpublished PhD Thesis, Queen Mary University of London.

Cashman, M.J, Piltto, F., Harvey, G.L., Wharton, G., Pusch, M.T. (2016) Combined stable-isotope and fatty-acid analyses demonstrate that large wood increases the autochthonous trophic base of a macroinvertebrate assemblage. Freshwater Biology $61 \quad$ (4), 549564. DOI: 10.1111/fwb.12727.

Chin, A., Laurencio, L.R., Daniels, M.D. Wohl, E., Urban, M.A., Boyer, K.L., Butt, A., Piegay, H. and Gregory, K.J. (2014) The significance of perceptions and feedbacks for effectively managing wood in rivers. River Reseach and Appications 30 (1), 98-111. DOI: 10.1002/rra.2617

Dadson, S.J., Hall, J.W., Murgatroyd, A., Acreman, M., Bates, P., Beven, K., Heathwaite, L., Holden, J., Holman, I.P., Lane, S.N., O’Connell, E., Penning-Rowsell, E., Reynard, N., Sear, D., 
Thorne, C., Wilby, R., 2017. A restatement of the natural science evidence concerning catchment-based "natural" flood management in the UK. Proc. R. Soc. A Math. Phys. Eng. Sci. 473, 20160706. DOI:10.1098/rspa.2016.0706

DEFRA (2011) $£ 110$ million revamp for England's rivers (online) https://www.gov.uk/government/news/110-million-revamp-for-englandsrivers (accessed 23 August 2012).

Downs, P.W. and Kondolf, G.M. (2002) Post-project appraisals in adaptive management of river channel restoration. Environmental Management 29 (4), 477-496. DOI:10.1007/s00267-0010035-x.

Environment Agency, 2017. Working with natural processes - the evidence base [WWW Document]. URL https://www.gov.uk/government/publications/working-with-naturalprocesses-to-reduce-flood-risk (accessed 23.3.18).

European Commision (2000) Directive 2000/60/EC ofthe European Parliament and of the Council of 23 October 2000 establishing a framework for the Community action in the field of water policy.

European Commission (2007) Directive 2007/60/EC of the European Parliament and of the Council of 23 October 2007 on the assessment and management of flood risks.

European Commission (2014) Directive 2014/101/EU of 30 October 2014 amending Directive 2000/60/EC of the European Parliament and of the Council establishing a framework for Community action in the field of water policy. Official Journal of the European Communities, L311, 32-35.

Gurnell, A.M., Gregory, K.J. and Petts, G.E. (1995) The role of coarse woody debris in forest aquatic habitats: Implications for management. Aquat. Conserv. Mar. Freshw. Ecosyst. 5 (2), 143-166. DOI:10.1002/aqc.3270050206.

Gurnell, A.M., Piégay, H., Swanson, F.J. and Gregory, S.V. (2002) Large wood and fluvial processes. Freshwater Biology 47, 601-619. DOI: 10.1046/j.1365-2427.2002.00916.x.

Harvey, G.L., Henshaw, A.J., Parker, C., Sayer, C.D., 2018. Re-introduction of structurally complex wood jams promotes channel and habitat recovery from overwidening: Implications for river conservation. Aquat. Conserv. Mar. Freshw. Ecosyst. 28, 395-407.

DOI:10.1002/aqc.2824.

Kondolf, G.M. (1998) Lessons learned from river restoration projects in California. Aquat. Conserv. Mar. Freshw. Ecosyst. 8, 39-52.

Morandi, B., Piégay, H., Lamouroux, N. and Vaudor, L. (2014) How is success or failure in river restoration projects evaluated? Feedback from French restoration projects. Journal of Environmental Management 137: 178-188. DOI: 10.1016/j.jenvman.2014.02.010. 
Pak, A. and Paroubek, P. (2010) Twitter as a Corpus for Sentiment Analysis and Opinion Mining. In: Proceedings of the Seventh conference on International Language Resources and Evaluation (LREC'10). European Language Resources Association (ELRA), Malta, pp. 1320-1326.

Palmer, M.A., Bernhardt, E.S., Allan, J.D., Lake, P.S., Alexander, G., Brooks, S., Carr, J., Clayton, S., Dahm, C.N., Follstad Shah, J., Galat, D.L., Loss, S.G., Goodwin, P., Hart, D.D., Hassett, B., Jenkinson, R., Kondolf, G.M., Lave, R., Meyer, J.L., O'Donnell, T.K., Pagano, L. and Sudduth, E. (2005). Standards for ecologically successful river restoration. Journal for Applied Ecology 45, 208-217. DOI: 10.1111/j.1365-2664.2005.01004.x

Piégay, H., Gregory, K.J., Bondarev, V., Chin, A., Dahlstrom, N., Elosegi, A., Gregory, S. V., Joshi, V., Mutz, M., Rinaldi, M., Wyzga, B. and Zawiejska, J. (2005) Public perception as a barrier to introducing wood in rivers for restoration purposes. Environmental Management 36 (5), 665674. DOI: 10.1007/s00267-004-0092-z.

Pilotto, F., Bertoncin, A., Harvey, G.L., Wharton, G. and Pusch, M.T. (2014) Diversification of stream invertebrate communities by large wood. Freshwater Biology 59 (12), 2571-

2583. DOI: $10.1111 /$ fwb.12454.

Pilotto, F., Harvey, G.L., Wharton, G., Pusch, M.T. (2016) Simple large wood structures promote hydromorphological heterogeneity and benthic macroinvertebrate diversity in low-gradient rivers. Aquatic Sciences 78 (4), 755-766. DOI 10.1007/s00027-016-0467-2.

River Restoration Centre, 2018. Manual of river restoration techniques [WWW Document]. URL http://www.therrc.co.uk/manual-river-restoration-techniques (accessed 21.3.18)

Ruiz-Villanueva, V., Piégay, H., Gurnell, A.M., Marston, R.E. and Markus, S. (2016) Recent advances quantifying the large wood dynamics in river basins: new methods and remaining challenges. Reviews of Geophysics 54, 611-652. DOI: 10.1002/2015RG000514.

Silge, J. and Robinson, D. (2016). "tidytext: Text Mining and Analysis Using Tidy Data Principles in R." JOSS 1(3). DOI: 10.21105/joss.00037.

Smith, B., Clifford, N.J. and Mant, J. (2014a). The changing nature of river restoration. WIRES Water 1, 249-261. DOI: 10.1002/wat2.1021.

Smith, B., Clifford, N.J. and Mant, J. (2014b). Analysis of UK river restoration using broad-scale data sets. Water and Environment Journal 28, 490-501. DOI: 10.1111/wej.12063.

Thompson, M.S.A, Brooks, S.J, Sayer, C.D, Woodward, G., Axmacher, J.C. and Gray, C. (2018) Large woody debris "rewilding" rapidly restores biodiversity in riverine food webs. Journal of Applied Ecology 55, 895-904. DOI: 10.1111/1365-2664.13013.

Wohl, E. 2014. A legacy of absence: Wood removal in US rivers. Progress in Physical Geography 38(5), 637-663. DOI: 10.1177/0309133314548091

Wohl, E., Bledsoe, B.P., Fausch, K.D., Kramer, N., Bestgen, K.R. and Gooseff, M.N. (2016). Management of Large Wood in Streams: An Overview and Proposed Framework for Hazard 
Evaluation. Journal of the American Water Resources Association 52(2), 315-335. DOI: 10.1111/1752-1688.12388.

Wohl, E., 2017. Bridging the gaps: An overview of wood across time and space in diverse rivers. Geomorphology 279, 3-26. DOI:10.1016/j.geomorph.2016.04.014

\section{Figures and Legends}

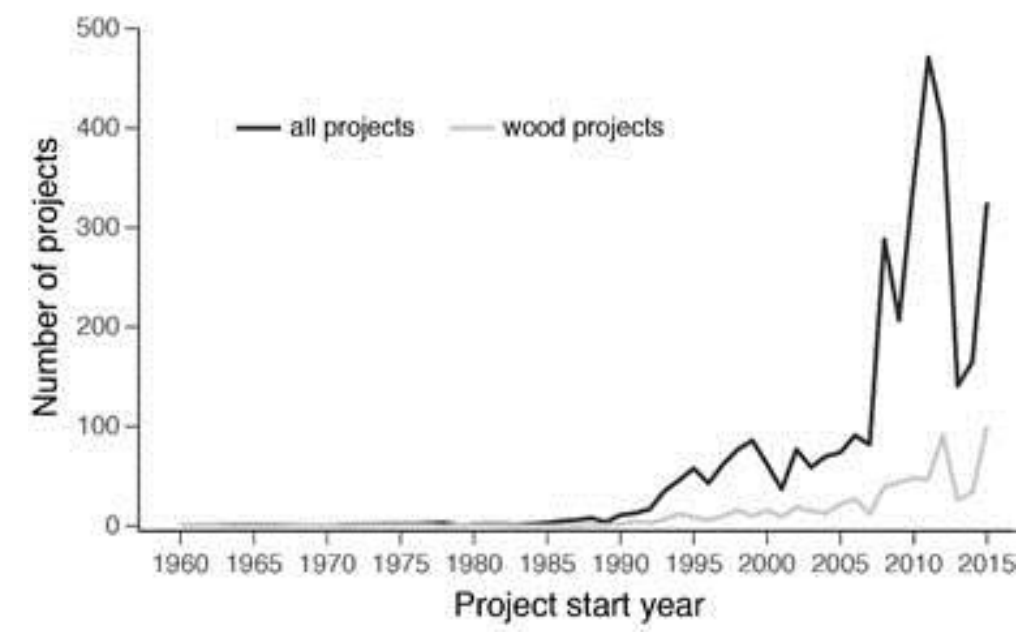

Figure 1: Temporal trends in the number of all UK restoration projects and subset of UK wood restoration projects contained in the NRRI by available start year. As project details are typically submitted to the NRRI 2-3 years after the project start date, we plotted trends up to 2015. 

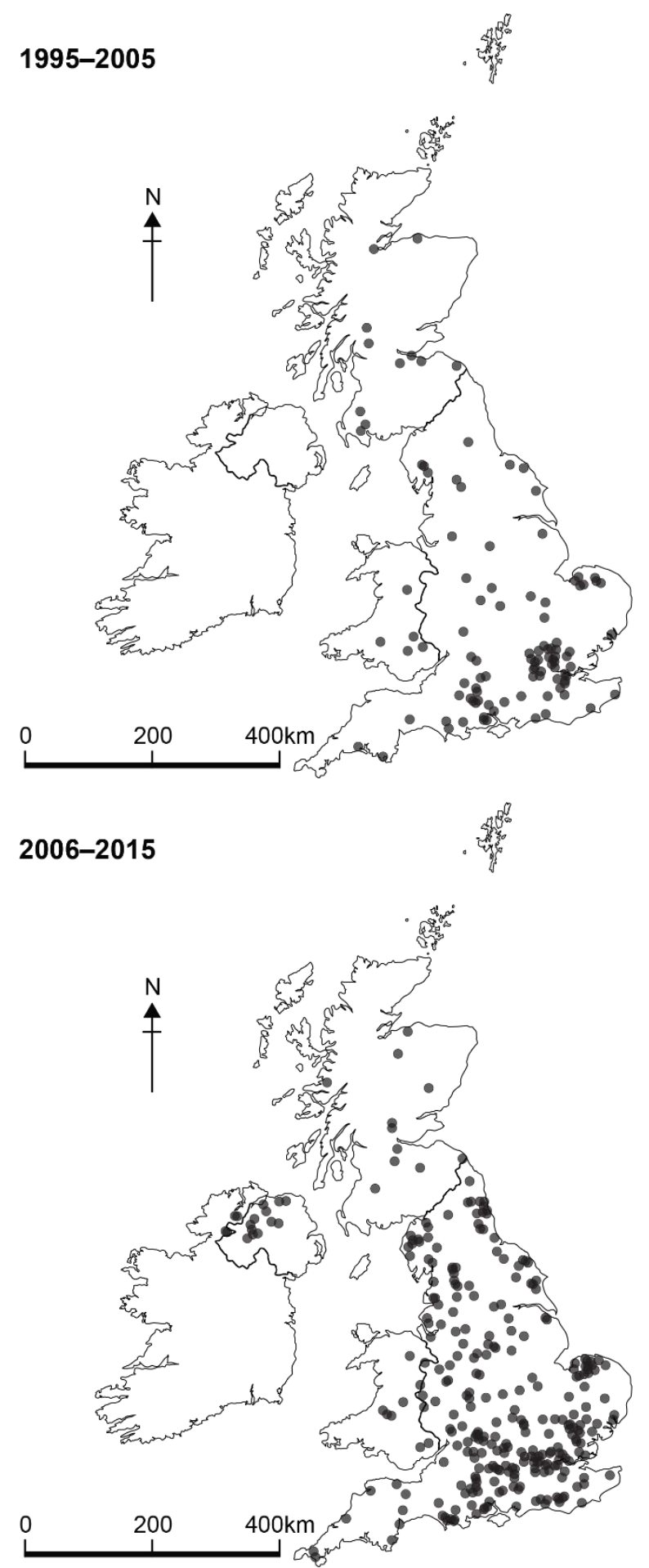

Figure 2: Location of restoration projects using wood implemented from 1995 - 2005 (a, top) and 2006 2016 (b, bottom) across the UK. 


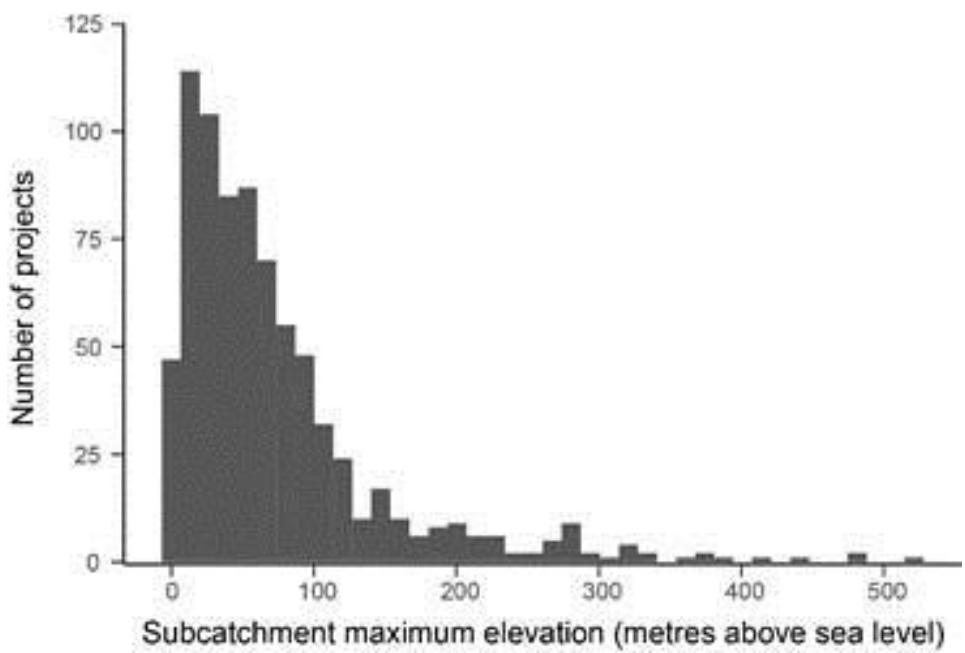

Figure 3: Frequency distribution of wood projects in the NRRI plotted by maximum sub-catchment altitude. 


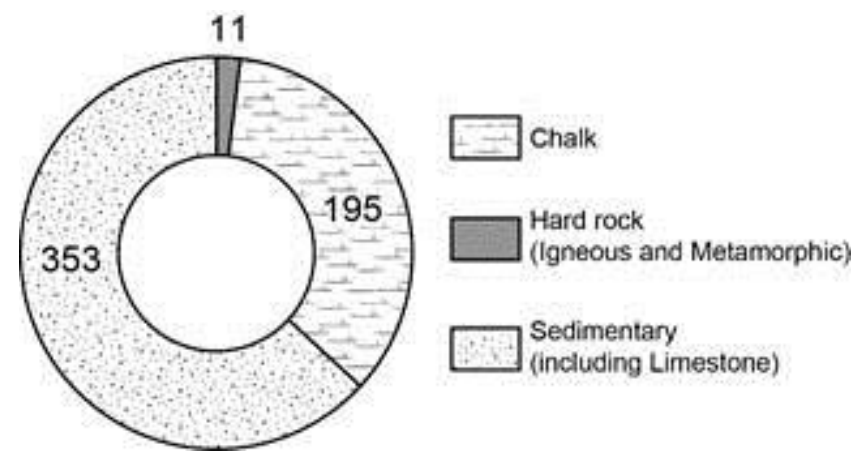

Figure 4: Number of wood projects in the NRRI according to geological category. 


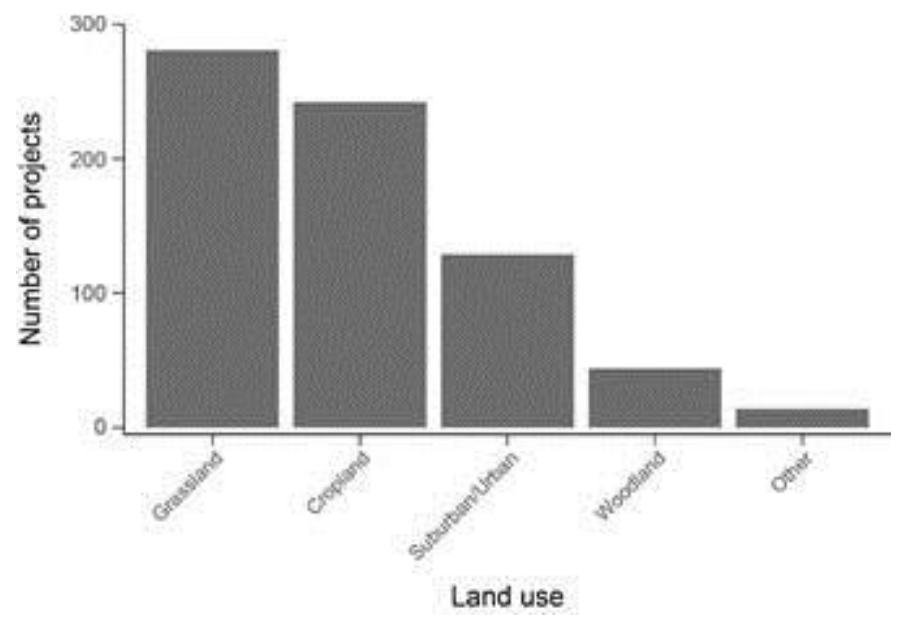

Figure 5: Dominant catchment land use for wood projects in the NRRI. 


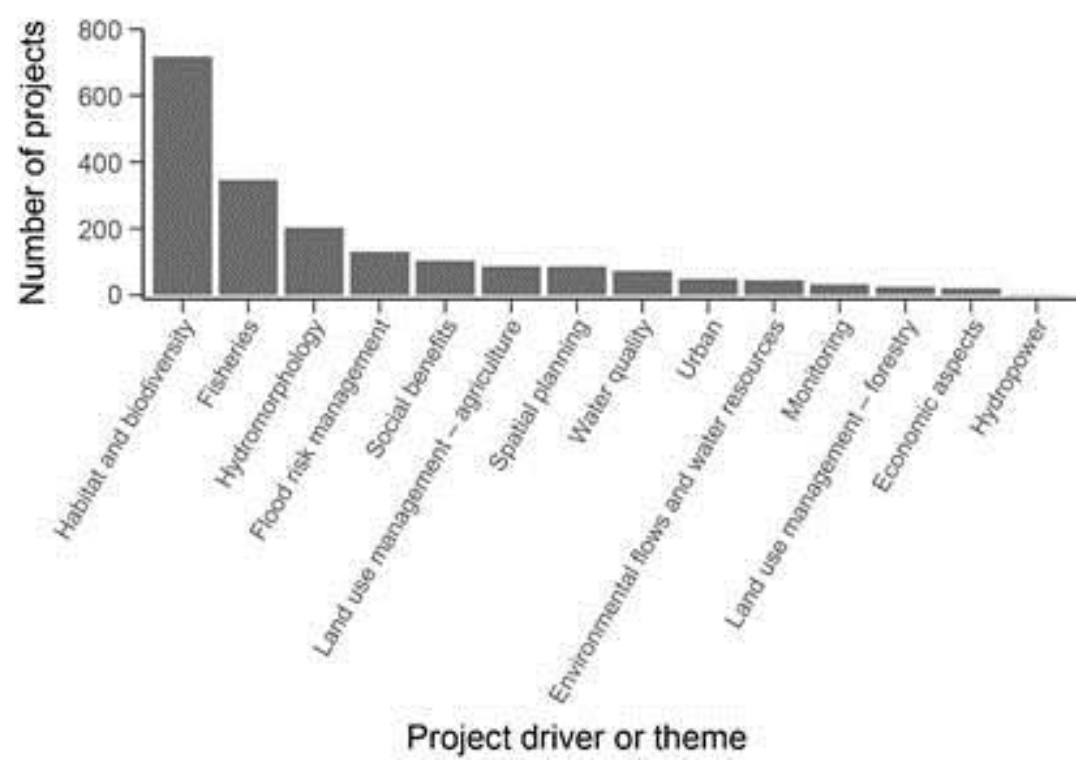

Figure 6: The key drivers or themes cited for wood projects in the NRRI. Note that as the selections were not mutually exclusive, multiple drivers could be listed for the same restoration project. 


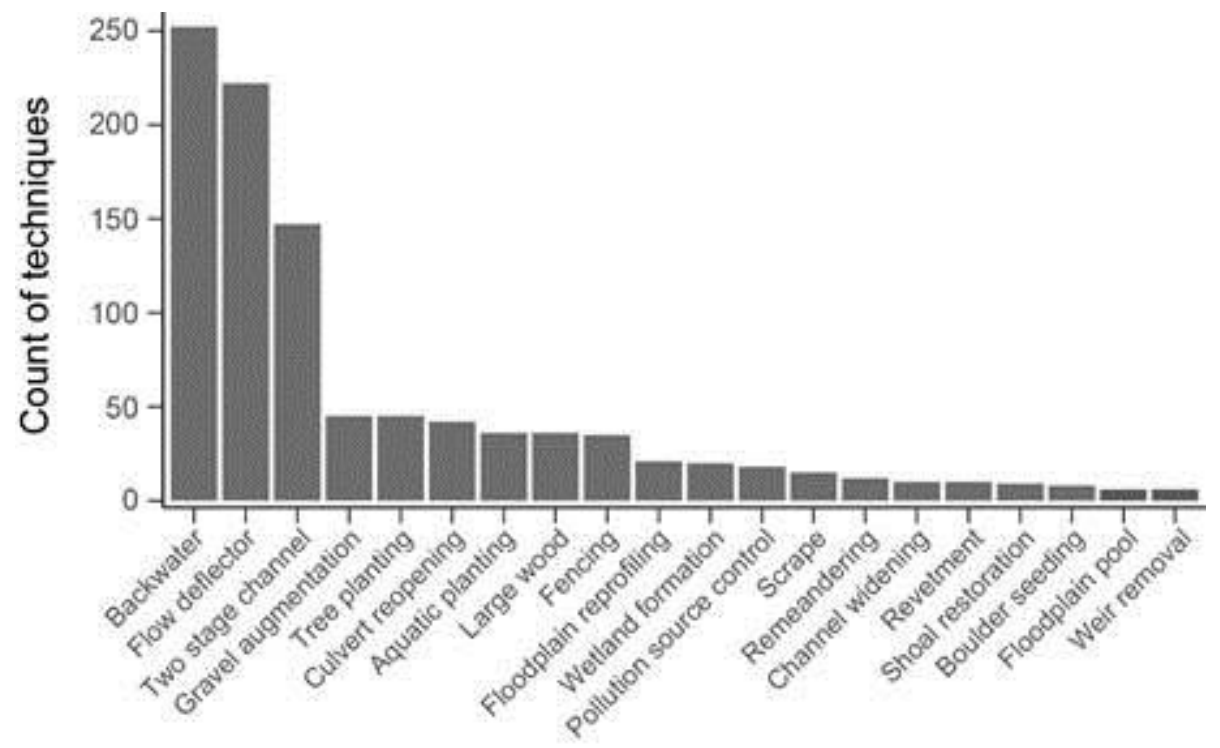

Restoration techniques

Figure 7: Twenty most common techniques employed in the restoration projects using wood from the NRRI. Note that as the selections were not mutually exclusive, multiple techniques could be listed for the same restoration project. 


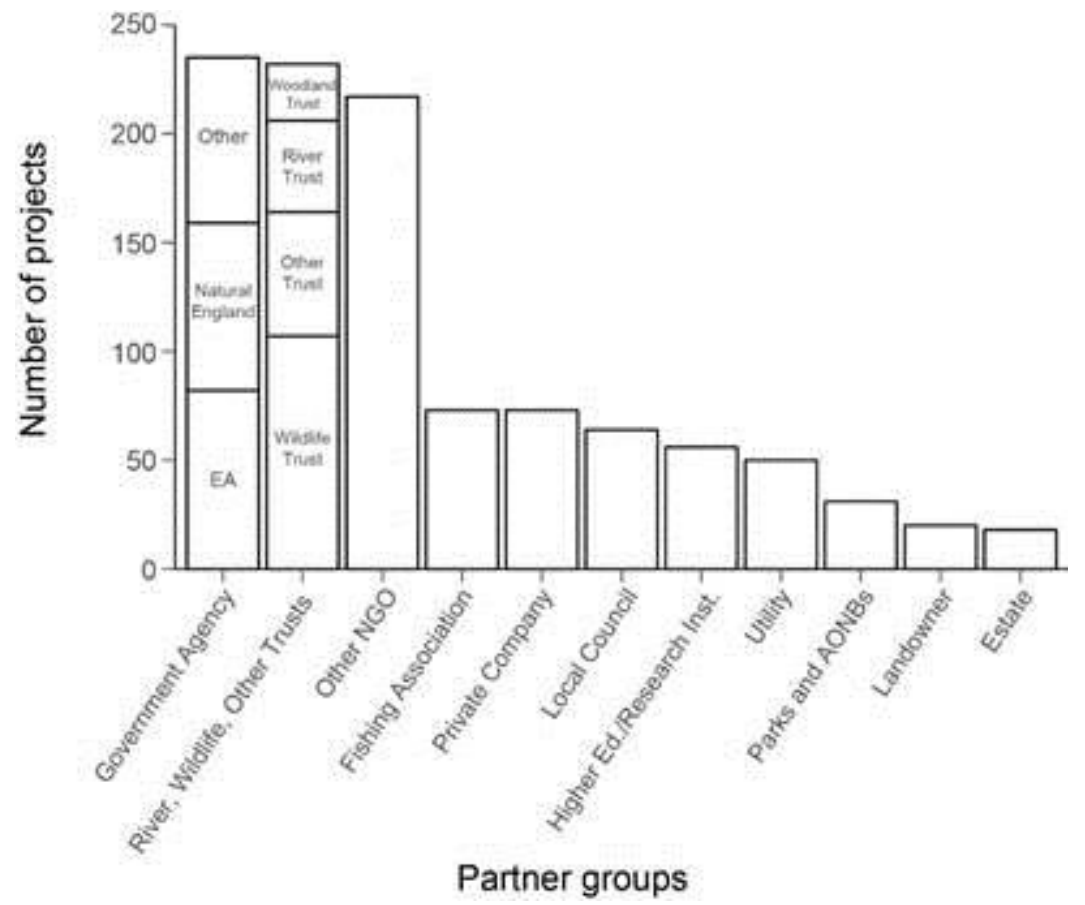

Figure 8: The most commonly involved partner groups in river restorations using wood reported in the NRRI. Note that as the selections were not mutually exclusive, multiple partners could be listed for the same restoration project. 


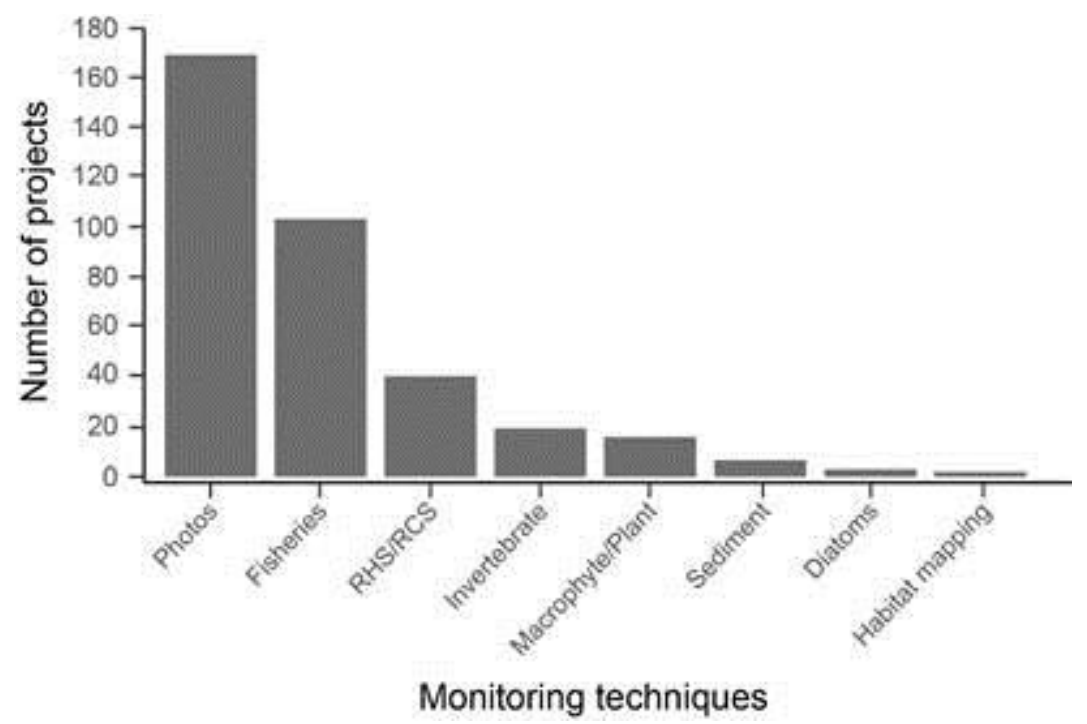

Figure 9: The most commonly used monitoring approaches in river restorations using wood reported in the NRRI. Note that as the selections were not mutually exclusive, multiple approaches could be listed for the same restoration project. 
(a)

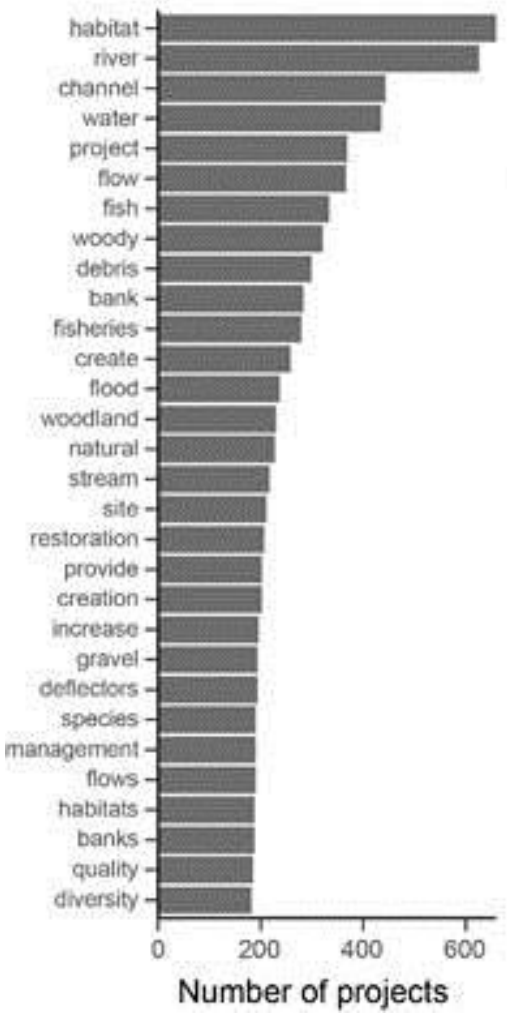

(b)

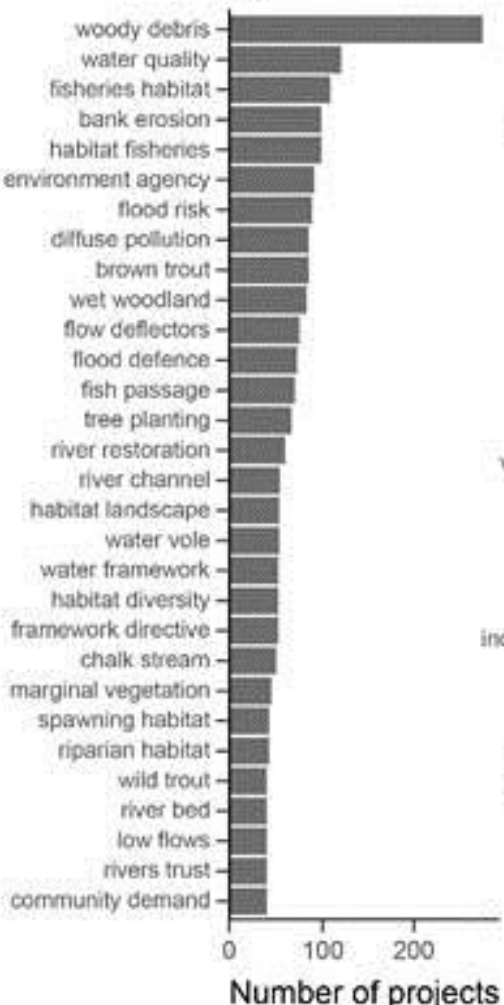

(c)

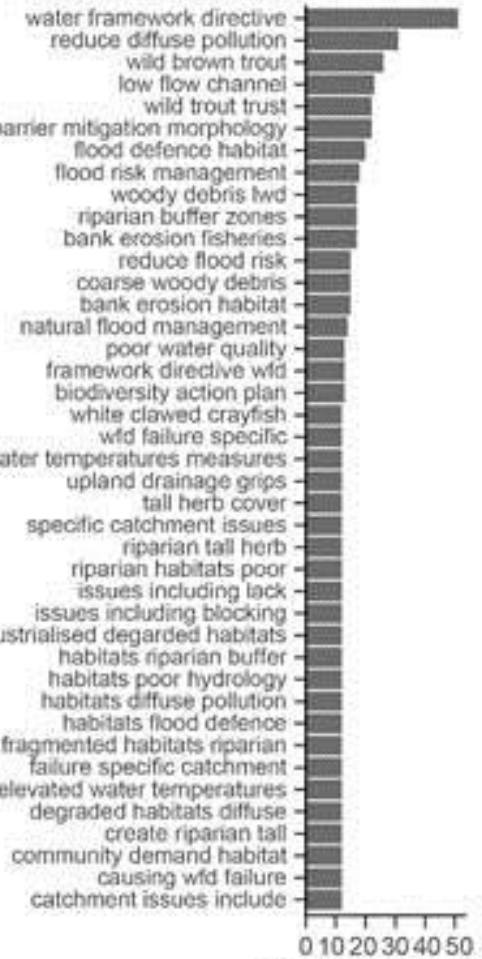

Number of projects

Figure 10: Graphical summaries of the n-gram text-mining analysis of the custom text from the Project Summary field: (a) Unigram plot; (b) Bigram plot; (c) Trigram plot. Project summaries were available for all 912 restoration schemes using LW identified from the NRRI. 


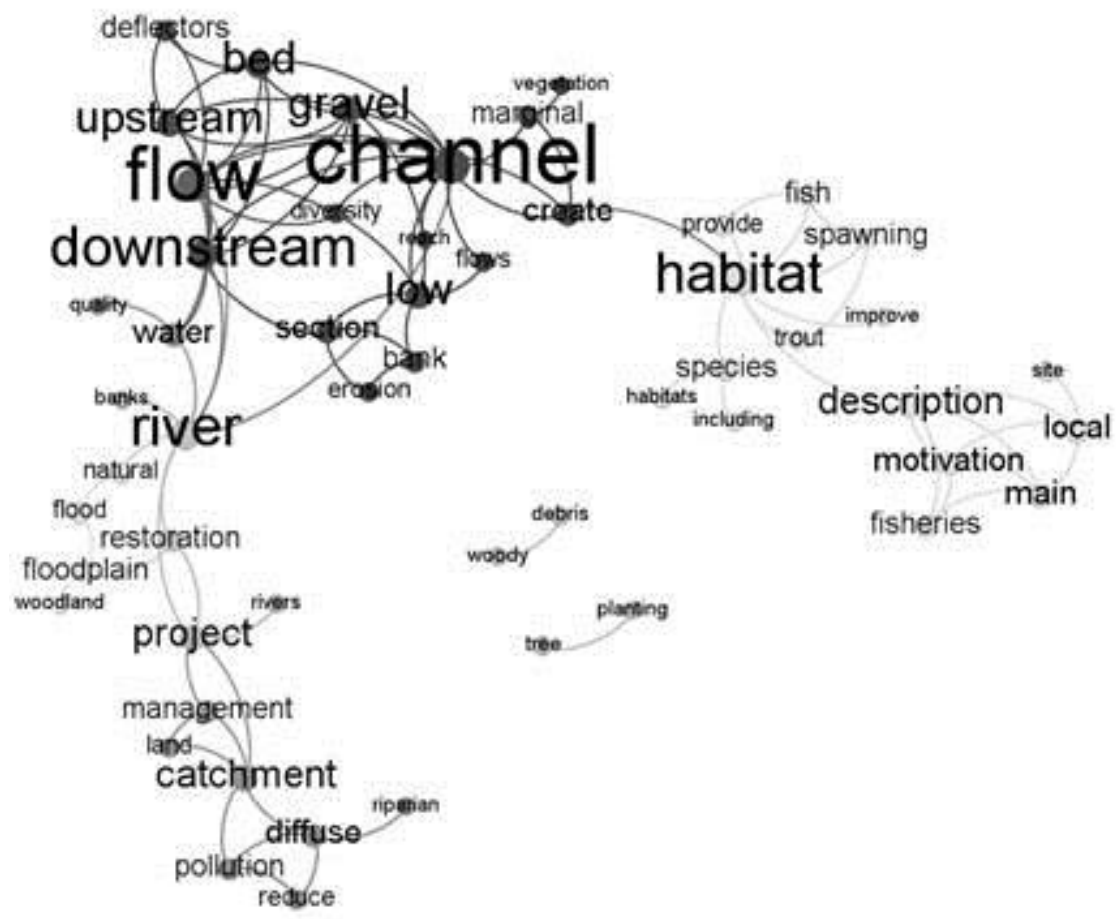

Figure 11: Correlation Network Plot of unigrams that occur in more than 200 individual Project Summary descriptions and have within-project word correlations of over 0.3 . Words are linked if they commonly co-occur, and size is scaled according to the number linkages (i.e. words are larger if correlated to many words). Clusters are groupings of co-occurring words and identify key thematic groupings of restorations using LW. 